\title{
Deregulation of miR-100, miR-99a and miR-199b in tissues and plasma coexists with increased expression of mTOR kinase in endometrioid endometrial carcinoma
}

Anna Torres ${ }^{1,2^{*}}$, Kamil Torres ${ }^{1,3}$, Anna Pesci $^{4}$, Marcello Ceccaroni ${ }^{5,6}$, Tomasz Paszkowski $^{2}$, Paola Cassandrini ${ }^{7}$, Giuseppe Zamboni ${ }^{4,8}$ and Ryszard Maciejewski ${ }^{1,9}$

\begin{abstract}
Background: Alterations of mTOR gene expression have been implicated in the pathogenesis of endometrioid endometrial cancer however only few studies explored the cause of increased mTOR activation in this malignancy. miRNAs are small, noncoding RNAs, which were proven to regulated gene expression at the posttranscriptional level. The study aimed to explore deregulation of miRNAs targeting mTOR kinase (miR-99a, miR-100 and miR-199b) as a possible cause of its altered expression in EEC tissues. In addition expression of the three miRNAs was investigated in plasma of EEC patients and was assessed in terms of diagnostic and prognostic utility.

Methods: We investigated expression of mTOR kinase transcripts in 46 fresh tissue samples. Expression of miR-99a, miR-100 and miR-199b was investigated in the same group of fresh samples, and in additional 58 FFPE sections as well as in 48 plasma samples using qPCR. Relative quantification was performed using experimentally validated endogenous controls.

Results: mTOR kinase expression was increased in EEC tissues and was accompanied by decreased expression of all three miRNAs. Down-regulation of the investigated miRNAs was discovered in plasma of EEC patients and miRNA signatures classified EEC tissues (miR-99a/miR-100/miR-199b) and plasma (miR-99a/miR-199b) samples with higher accuracy in comparison to single miRNAs. We also revealed that miR-100 was an independent prognostic marker of overall survival.

Conclusions: We conclude that increased expression of mTOR kinase coexists with down-regulation of its targeting miRNAs, which could suggest a new mechanism of mTOR pathway alterations in EEC. In addition, our findings implicate that miRNA signatures can be considered promising biomarkers for early detection and prognosis of endometrioid endometrial carcinoma.
\end{abstract}

Keywords: mTOR, microRNA, miRNA, Endometrial cancer, Plasma

\footnotetext{
* Correspondence: anna.torres@wp.pl

'Laboratory of Biostructure, Chair and Department of Human Anatomy,

Medical University of Lublin, Jaczewskiego 4, Lublin, Poland

${ }^{2}$ III Chair and Department of Gynecology, Medical University of Lublin,

Jaczewskiego 8, Lublin, Poland

Full list of author information is available at the end of the article
} 


\section{Background}

Endometrial cancer is the most common malignant tumor of the female reproductive tract and the fourth most often occurring malignancy in the female population of developed countries [1,2]. The incidence of endometrial cancer has increased in the Great Britain, as it was reported by Evans et al. [3]. Similar trend was also observed in Poland basing on the data provided by Polish Cancer Registry [4]. Most endometrial cancers are diagnosed in early clinical stages and can be managed surgically with good results, however there is still a number of cases with bad prognosis due to lack of effective treatment for advanced, recurrent or disseminated disease. Approximately $80 \%$ of endometrial cancers are of endometrioid histology [5]. Etiology of endometrioid endometrial tumors has been connected with alteration of several genes [6,7]. In particular alterations of PTEN (phosphatase and tensin homologue) gene and its product were widely investigated and loss of PTEN activity was proven to induce increased AKT (v-akt murine thymoma viral oncogene homolog; racbeta serine/threonine protein kinase) and mTOR activity [8-10].

mTOR (mechanistic target of rapamycin) gene is located on chromosome 1 (locus 1p36.2) and encodes for the serine/threonine kinase, which plays a role in cellular response to various stress factors including decreased ATP level, hypoxia and DNA damage. mTOR is involved in the regulation of translation process, cellular proliferation and differentiation [11,12]. It is of particular interest that mTOR kinase, which integrates several cellular pathways activated in the response to changes in ATP and growth factors levels as well as those responsible for cell growth and proliferation, becomes deregulated in many malignant diseases including endometrial cancer [13-16]. It has been proven that it is activated via AKT phosphorylation both directly and indirectly through inactivation of TSC2 (tuberous sclerosis complex 2) [17]. A negative regulation of mTOR activity involves AMPK (5'-AMP-activated protein kinase), which inhibits mTOR actions through phosphorylation and activation of TSC1/TSC 2 complex $[18,19]$. Increased expression and activity of mTOR kinase in endometrial cancer has been connected with the loss of PTEN, LKB1 (Liver Kinase B1) and TSC2 activity as well as increased expression of Phospholipase D1 [20]. Nevertheless, such alterations were not uniformly reported in all EEC cases therefore other mechanisms could be involved in the regulation of mTOR pathway activity including posttranscriptional regulation of mTOR expression, which involves microRNAs (miRNAs). miRNAs are small, non-coding RNA molecules composed of 19 to 25 nucleotides which were proven to regulate gene expression during posttranscriptional stages [21]. miRNAs play important roles in development, cell proliferation and differentiation as well as cell cycle control. Several miRNAs were also associated with the pathogenesis of various malignancies including endometrial cancer [22]. Guo et al. have recently proven that in mammalian cells miRNAs act predominantly through decreasing target mRNA levels [23]. Therefore down-regulation of miRNAs targeting genes involved in carcinogenesis is likely to favor initiation of malignant transformation. Alterations of genes, which are upstream to mTOR and could be responsible for its activation, are not uniformly present in all EEC cases [5]. Therefore in the presented study we aimed to assess mTOR kinase mRNA levels and to explore possible association between altered expression of mTOR kinase transcripts and its targeting miRNAs, miR-99a, miR-100 and miR199b, which were chosen basing on the three opensource in silico algorithms (Target Scan, DIANA microT v. 3.0, miRanda). Expression of the three miRNAs was also investigated in plasma of EEC patients and was assessed in terms of their diagnostic and prognostic utility.

\section{Methods}

\section{Patients}

Altogether one hundred and twenty two patients were included in the study. Patients were hospitalized in gynecological departments of Medical University of Lublin (Poland) and Ospedale Sacro Cuore Don Calabria (Negrar, Italy). Study encompassed 46 tissue samples and 58 formalin-fixed paraffin-embedded specimens as well as 48 blood samples. Study design was revised and approved by Medical University of Lublin Ethical Committee and informed consent was obtained from each study participant. The EEC group consisted of 77 patients: 73 were included in tissue part of the study, whereas material obtained from the remaining four was used only for miRNA expression analysis in plasma. Control group for the tissue part of the study included 31 participants operated on due to benign gynecological pathologies not connected with endometrium and control group for the plasma part of the study included 14 women with no previous history of cancer or endometrial pathology. All patients with EEC were submitted to total hysterectomy and bilateral oophorectomy and were subsequently treated by radiotherapy and/or chemotherapy according to FIGO guidelines. Lymphadenectomy was performed in 44 patients (57\%). None of the patients had received neoadiuvant therapy. 2009 revised FIGO classification was used to determine clinical stage of the disease [24]. Table 1 presents detailed characteristics of the patients included in the study. $85.3 \%$ of patients with EEC were postmenopausal, whereas most 
Table 1 Clinicopathological characteristics of the patients

\begin{tabular}{|c|c|c|}
\hline Characteristic & $\begin{array}{l}\text { Number of } \\
\text { EEC patients }\end{array}$ & $\begin{array}{l}\text { Number of } \\
\text { control patietns }\end{array}$ \\
\hline \multirow[t]{2}{*}{ Average age (years) } & 62.8 years $\pm 10.14^{*}$ & $44.78 \pm 7.19^{*}$ \\
\hline & (95\% Cl 59.75 - 64.38) & $(95 \%$ Cl $42.51-47.05)$ \\
\hline \multicolumn{3}{|l|}{ FIGO stage } \\
\hline IA & 32 & \\
\hline IB & 18 & \\
\hline$\|$ & 5 & \\
\hline$\| \mathrm{A}$ & 2 & \\
\hline$\| \mathrm{II}$ & 3 & \\
\hline$\| I C 1$ & 10 & \\
\hline $\mathrm{IIC} 2$ & 5 & \\
\hline IVA & 1 & \\
\hline IVB & 1 & \\
\hline \multicolumn{3}{|l|}{ Grade } \\
\hline 1 & 29 & \\
\hline 2 & 30 & \\
\hline 3 & 18 & \\
\hline \multicolumn{3}{|l|}{ Myometrial invasion } \\
\hline $\begin{array}{l}<0.5 \text { of myometrial } \\
\text { thickness }\end{array}$ & 36 & \\
\hline $\begin{array}{l}\geq 0.5 \text { of myometrial } \\
\text { thickness }\end{array}$ & 41 & \\
\hline \multicolumn{3}{|l|}{ Lymph node metastasis } \\
\hline absent & 15 & \\
\hline present & 29 & \\
\hline $\begin{array}{l}\text { lymphadenectomy } \\
\text { not performed }\end{array}$ & 33 & \\
\hline \multicolumn{3}{|l|}{ Relapse } \\
\hline absent & 10 & \\
\hline present & 24 & \\
\hline
\end{tabular}

* $T$-test, $\mathrm{p}<0.001$.

women in the tissue control group were premenopausal (81.6\%). The plasma control group comprised of equal numbers of pre- and postmenopausal cases.

\section{Samples}

Fresh tissues were sampled within 15 minutes from excision of the uterus. Tissues were immediately stored in RNAlater (Ambion) and incubated in this solution for 24 hours in $4^{\circ} \mathrm{C}$. Tissues were then stored in $-80^{\circ} \mathrm{C}$ until RNA isolation.

FFPE tissues used for the study were fixed with $10 \%$ formalin and stored for maximum 10 years. All the original hematotoxylin and eosin (H\&E)-stained sections were reviewed by a gynecopathologist (A.P.). EEC specimens were classified, according to the 2002 WHO classification in G1, G2 or G3. Specimens containing at least $70 \%$ of cancer cells, were selected and micro dissected.
Samples of the normal endometrium (NE) included both proliferative and secretory phase epithelium.

All blood samples were collected from antecubital vein using closed blood collection system (S-Monovette (EDTA), Sarstedt) and centrifuged for 15 minutes $\left(3200 \mathrm{rpm}, 19^{\circ} \mathrm{C}\right)$. Plasma was collected, aliquoted and stored in $-80^{\circ} \mathrm{C}$.

\section{RNA isolation}

40 to $80 \mathrm{mg}$ of macro dissected tissues stored in RNAlater was homogenized in a rotor -stator homogenizer and RNA was isolated using mirVANA ${ }^{\mathrm{TM}}$ miRNA Isolation Kit (Ambion) according to manufacturer's protocol.

RNA isolation from FFPE tissues was performed using Recover All $^{\text {Tw }}$ Total Nucleic Acid Isolation Kit for FFPE Tissues (Ambion) according to the protocol provided by the manufacturer. As suggested in the protocol, $10 \mu \mathrm{m}$ FFPE sections were used for isolation procedure. RNA isolated from tissues underwent DNase treatment using Turbo DNAase Kit (Ambion).

Isolation of RNA from plasma was performed using mirVANA $^{\mathrm{TM}}$ PARIS Kit (Ambion) and $400 \mathrm{~mL}$ of plasma. $5 \mathrm{fmol} / \mu \mathrm{l}$ of each of the following synthetic Caenorhabditis elegans oligonucleotides : cel-miR-39, celmiR-54, cel-miR-238 was spiked into plasma sample after addition of $2 x$ Denaturating Solution. From that point isolation was performed according to manufacturer's protocol. Elution was performed with $52.5 \mu \mathrm{l}$ of RNase, DNase-free water. Isolation of RNA from plasma was conducted in duplicates. RNA was stored in $-80^{\circ} \mathrm{C}$.

Concentration and purity of RNA was inspected using spectrophotometer (Biophotometer with Hellma Tray Cell, Eppendorf) and RNA integrity was checked using Bioanalyzer 2100 (Agilent Technologies Inc.) and Agilent RNA Nano kit. In case of RNA isolated from fresh frozen tissues only samples with $\mathrm{RIN} \geq 6$ were used in downstream applications. In case of RNA extracted from FFPE the average RIN was 3.45. 260/280 ratio of all tissue samples ranged between 1.8 - 2.2.

\section{Reverse transcription of total RNA}

Total RNA (500 ng) was reverse transcribed in triplicates using Precision nanoScript Reverse Transcription kit (Primer Design) according to manufacturer protocol. Briefly, a mix of $9 \mu \mathrm{l}$ of RNA o $1 \mu \mathrm{l}$ of random nonamers was incubated in $65^{\circ} \mathrm{C}$ for $5 \mathrm{~min}$. Then the mixture was combined with $2 \mu \mathrm{l}$ nanoScipt buffer 10x, $1 \mu \mathrm{l} 10 \mathrm{mM}$ nucleotides, $2 \mu \mathrm{l} 100 \mathrm{mM}$ DTT, $1 \mu \mathrm{l}$ reverse trancriptase and $4 \mu \mathrm{l}$ water. Reactions were then incubated in $25^{\circ} \mathrm{C}$ for $5 \mathrm{~min}$, in $55^{\circ} \mathrm{C}$ for $20 \mathrm{~min}$ and in $75^{\circ} \mathrm{C}$ for $15 \mathrm{~min}$.

Reactions were carried in Master cycler ep gradient $\mathrm{S}$ (Eppendorf) and stored in $-20^{\circ} \mathrm{C}$. 


\section{Real-time qPCR for $\mathrm{mTOR}$ and PTEN expression}

Amplification of mTOR, PTEN and three reference genes (SDHA, UBC, CYC1) was performed in $20 \mu \mathrm{L}$ reactions. Each reaction consisted of: $1 \mu \mathrm{L} 20 \mathrm{x}$ TaqMan ${ }^{\circledR}$ Gene Expression Assay (mTOR Hs00234508, PTEN Hs02621230_s1, SDHA Hs00188166_m1, UBC Hs00824723_m1, CYC1 Hs00357717_m1, Applied Bios stems), $4 \mu \mathrm{L}$ cDNA (50 ng), $10 \mu \mathrm{L} 2 \mathrm{x}$ TaqMan ${ }^{\circledR}$ Gene Expression Master Mix (Applied Bios stems) and $5 \mu \mathrm{L}$ water. Reactions were carried out in duplicates in Rotor Gene 6000 2-plex HRM thermo cycler (Corbett Research) using the following protocol: $95^{\circ} \mathrm{C}$ for $10 \mathrm{~min}$ and $45 \mathrm{cycles}$ of $95^{\circ} \mathrm{C}$ for $15 \mathrm{sec} / 55^{\circ} \mathrm{C}$ for $60 \mathrm{sec}$.

$\mathrm{Cq}$ values were determined with the threshold value of 0.03 and automatically defined baseline.

\section{miRNA Reverse transcription and real-time qPCR}

RNA isolated from tissues was reverse transcribed in $7.5 \mu$ reactions, which consisted of $3.5 \mu \mathrm{L}$ RT Master Mix $(0.75 \mu \mathrm{L} 10 \times$ RT Buffer, $0.075 \mu \mathrm{L} 100 \mathrm{mM}$ dNTPs, $0.5 \mu \mathrm{L}$ Multiscribe ${ }^{\mathrm{TM}}$ Reverse Transcriptase, $0.095 \mu \mathrm{L}$ RNase Inhibitor $(20 \mathrm{U} / \mu \mathrm{L}), 2.08 \mu \mathrm{L}$ nuclease-free water, $1.5 \mu \mathrm{L}$ of specific starters and $2.5 \mu \mathrm{L}$ RNA (5 ng). Plasma RNA was reverse transcribed in $5 \mu \mathrm{l}$ reactions: $0.5 \mu \mathrm{L} 10$ x RT Buffer, $0.05 \mu \mathrm{L} 100 \mathrm{mM}$ dNTPs, $0.33 \mu \mathrm{L}$ Multiscribe ${ }^{\mathrm{TM}}$ Reverse Transcriptase, $0.063 \mu \mathrm{L}$ RNase Inhibitor $(20 \mathrm{U} / \mu \mathrm{L}), 1.387 \mu \mathrm{L}$ nuclease-free water, $1 \mu \mathrm{L}$ specific starters and $1.67 \mu \mathrm{L}$ of RNA eluate. RT reactions were carried out in triplicates using following protocol: $16^{\circ} \mathrm{C}$ for $30 \mathrm{~min}$, followed by $42^{\circ} \mathrm{C}$ for $30 \mathrm{~min}$ and $85^{\circ} \mathrm{C}$ for 5 min in Master cycler ep gradient $\mathrm{S}$ (Eppendorf) and stored in $-20^{\circ} \mathrm{C}$.

qPCR reactions for miRNA expression analysis were prepared as follows: $0.5 \mu \mathrm{L}$ 20x TaqMan ${ }^{\circledR}$ MicroRNA Assay (assay IDs, miR-99a 000435, miR-100 000437, miR-199b 000500, Applied Bios stems), $4.5 \mu \mathrm{L}$ RT product (dilution 1:15 for tissues and 1:7.5 for plasma), $5 \mu \mathrm{L}$ 2x TaqMan $^{\circledR}$ Universal PCR Master Mix (Applied Biosystems).

All qPCR reactions were performed in duplicates in ViiA7 Real-Time PCR System (Applied Biosystems) using the following PCR protocol: $95^{\circ} \mathrm{C}$ for $10 \mathrm{~min}$ and 45 cycles of $95^{\circ} \mathrm{C}, 15 \mathrm{~s} / 60^{\circ} \mathrm{C}, 60 \mathrm{~s}$. Positive and negative control reactions as well as inter-plate calibrator (IPC) reactions were carried out on each plate.

$\mathrm{Cq}$ values were determined with the threshold value of 0.2 and automatically defined baseline.

\section{Normalization of qPCR data}

Before statistical analysis qPCR data were normalized with inter-plate calibrators to adjust for run-to-run differences and corrected for reaction efficiency [25].

Efficiency of each primer/probe sets was determined by performing standard curve with six-fold dilution of a pooled cDNA template.
Expression of mTOR and PTEN was then further normalized using geometric mean of the expression of three stable reference genes: SDHA, UBC and CYC1, which were experimentally chosen from the panel of 12 candidate genes. Similarly, tissue miRNA qPCR data were normalized using geometric mean of the expression of three experimentally chosen endogenous controls RNU48, RNU44 and U75. Choice of those specific snRNA was performed from the panel consisting of 12 non-coding RNAs, which were previously described to be stably expressed in tissues or were used in endometrial cancer qPCR studies [26-29].

Additional normalization step was implemented in case of plasma miRNA expression data in order to adjust for the variation in RNA extraction. Raw data were initially normalized to expression of three synthetic oligonucleotides matching the sequences of Caenorhabditis elegans miRNAs: cel-miR-39, cel-miR-54, cel-miR-238 using median normalization procedure as it was previously described [30,31].

Five experimentally chosen stable endogenous controls: miR-93, miR-26b, miR-192, miR-103a, miR-142$3 p$ were then used for normalization of plasma miRNA expression data. Reference miRNAs were chosen from the panel comprising nine candidate miRNAs (miR-93, miR-26b, miR-192, miR-103a, miR-142-3p, miR-92a, miR-638, miR-16 and miR-451), which were suggested to be highly and stably expressed in plasma [32-35]. Endogenous controls used for both mRNA and miRNA relative expression studies were chosen using two statistical tools Norm Finder and geNorm and validation studies were performed in groups consisting of 45 tissue samples and 48 plasma samples [36,37].

\section{Statistical analysis of qPCR data}

After normalization data were log transformed. Results are presented as mean with $95 \%$ confidence intervals (95\% CI) or a fold change (FC) with $95 \%$ CI.

D'Agostino-Pearson test and Fisher test were used to assess normal distribution of data and equality of variances, respectively. Comparisons between the groups were performed with Student $t$-test (with or without Welch correction) and ANOVA or with nonparametric tests (Mann-Whitney and Kruskal-Wallis) depending on the results of the normality assessment. Spearman coefficient was applied to determine correlation between expressions of miRNAs.

Receiver-operating characteristics (ROC) curves were constructed and sensitivity, specificity as well as positive and negative predictive values were determined to assess accuracy of miRNA expression in classifying EEC and control samples.

Multivariate logistic regression analysis was applied to inspect if miRNA signatures composed of more than 
one miRNA present better accuracy in discriminating between tumor and control samples. $\chi^{2}$ Wald test and Hosmer-Lemeshow test were used to evaluate regression models.

Survival analysis was performed using univariate and multivariate Cox proportional hazard models and Kaplan-Meier estimator. Survival curves were compared with log-rank test. Level of significance was set for $\mathrm{p} \leq 0.05$ and all statistical tests were two-sided. GenEx 5.3.4. (MultiD) and MedCalc (MedCalc Software) version 12.2.1. were utilized to perform data analysis.

\section{Results}

mTOR kinase and PTEN mRNA expression in EEC tissues We found an increased expression of mTOR kinase mRNA in EEC tissues (FC 1.54, 95\% CI 1.01-2.36, $\mathrm{p}=0.033$ ) (Figure 1). Comparison of groups distinguished based on histological grade, FIGO stage and myometrial invasion did not revealed any significant differences. Nevertheless, when compared separately, G1 samples were not significantly different in comparison to control samples in regards to mTOR expression, whereas in G2 samples or combination of G2 and G3 samples mTOR kinase transcripts levels were significantly up-regulated $(\mathrm{p}=0.05$ and 0.022 , respectively).

Expression of mTOR was also compared between proliferative and secretory endometrium within the control group and no significant differences were found between the groups.
Expression of PTEN mRNA, a negative upstream regulator of mTOR pathway, was not changed in the investigated set of EEC tissues (FC 1.38, 95\%CI 0.600$3.040, \mathrm{p}=0.38$ )

\section{miRNAs targeting mTOR kinase are decreased in EEC tissues}

miR-99a, miR-100 and miR-199b were significantly down-regulated in EEC tissues (Figure 2). The lowest expression was attributed to miR-199b (FC 3.52, 95\% CI 1.59-7.79, $\mathrm{p}=0.002)$. In addition, its downregulation in EEC tissues correlated with advanced histological grade and was the lowest in G3 samples. The difference between G2 and G3 samples was significant $(\mathrm{p}=0.04)$ and the difference between combined G1 and G2 samples and G3 was close to statistical significance $(\mathrm{p}=0.056)$.

miR-99a was more than threefold decreased (FC 3.29, 95\% CI 1.49-7.26, $\mathrm{p}=0.007$ ) in EEC tissues. Comparison between groups distinguished based on histological grading revealed the lowest miR-99a expression in G3 samples, which was significantly different from G2 samples $(\mathrm{p}=0.047)$ and combined G1 and G2 samples $(\mathrm{p}=0.029)$. Neither miR-99a nor miR-199b expression correlated with other clinic pathological characteristics including FIGO stage, myometrial invasion, lymph node metastasis and relapse.

miR-100 was decreased by the factor 2.56 (9\% CI 1.275.23, $\mathrm{p}=0.02$ ) and no correlation was found between its expression and clinic pathological characteristics of the disease.

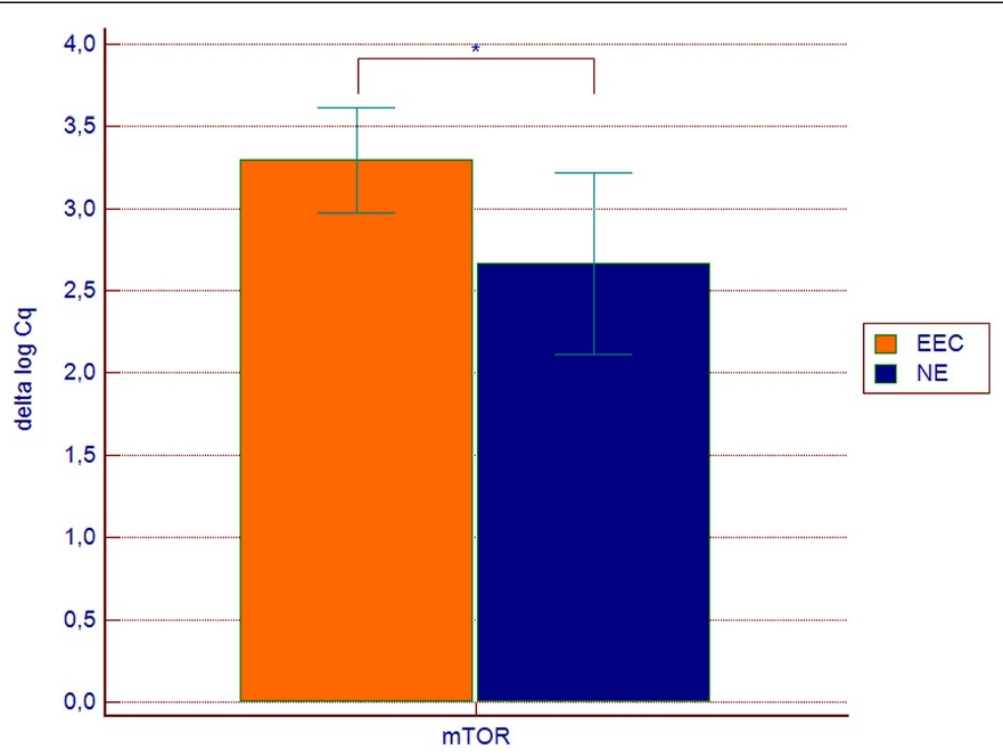

Figure 1 mTOR gene expression in endometrioid endometrial cancer samples $(n=31)$ and in the control group $(n=15)$. Values are presented in the log scale; ${ }^{*} p=0.033$. 


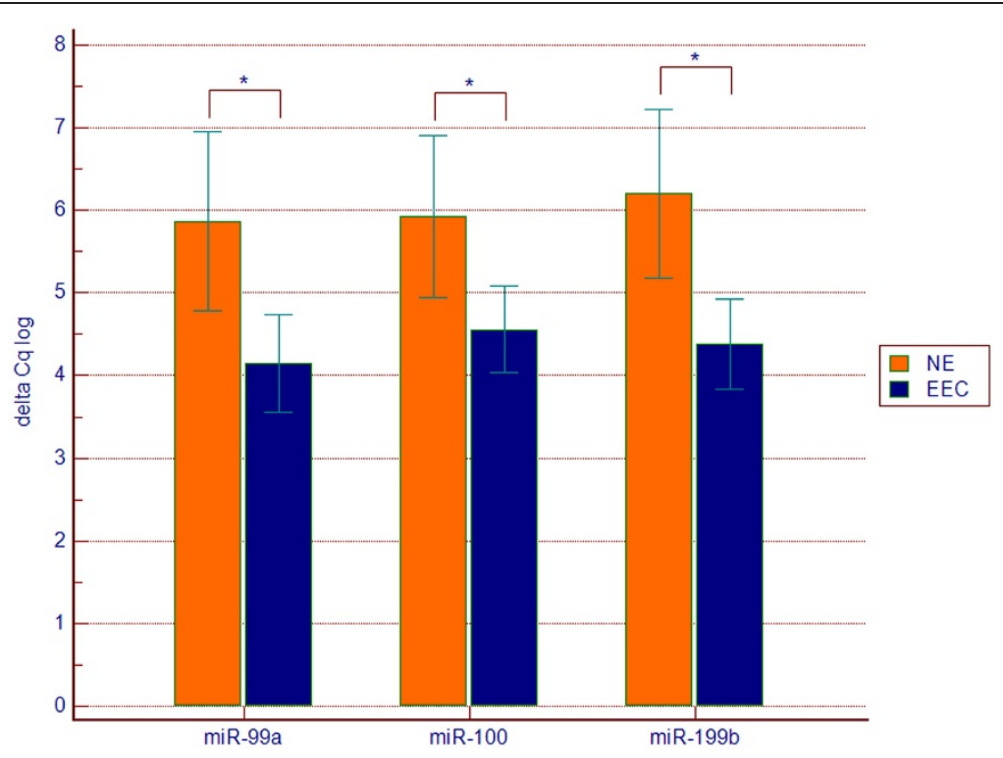

Figure 2 Expression of miR-99a, miR-100 and miR-199b in endometrioid endometrial cancer $(E E C n=73)$ tissue samples in comparison to control group (NE $\mathbf{n}=\mathbf{3 1}$ ). Values are presented in the log scale; ${ }^{*} p=0.007$ (miR-99a), ${ }^{*} p=0.02\left(\right.$ miR-100), ${ }^{*} p=0.002$ (miR-199b).

Decreased expression of three studied miRNAs significantly correlated with increased mTOR expression in EEC tissues $(\mathrm{r}=-0.36, \mathrm{p}=0.022$ for miR-99, $\mathrm{r}=-0.36$, $\mathrm{p}=0.023$ for miR-100, $\mathrm{r}=-0.2, \mathrm{p}=0.023$ for miR-199b). In addition there was a significant and very strong correlation between miR-99a and miR-100 expression, both in EEC and control samples groups $(\mathrm{r}=0.94, \mathrm{p}<0.0001)$, whereas no correlation was found between any of the two miRNAs and miR-199b.

Comparison of miR-99a, miR-100 and miR-199b expression performed between proliferative and secretory endometrium within the control group did not reveal any significant differences.

miRNAs targeting mTOR kinase are up-regulated in plasma of EEC patients

Expression of all three studied miRNAs was significantly increased in plasma of EEC patients (Figure 3). The highest fold change in expression was attributed to miR199b, which was almost three times increased (FC 2.89, 95\% 1.6-5.23, $\mathrm{p}=0.0007)$. Nearly two-fold increase was detected in case of miR-99a expression (FC 1.96, 95\% CI

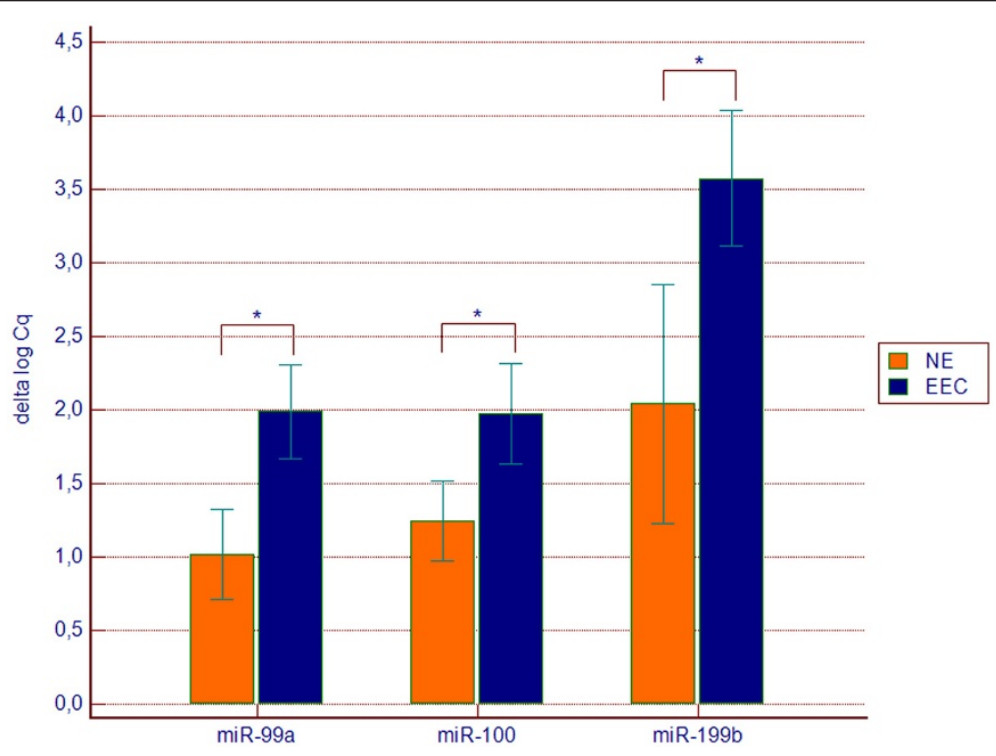

Figure 3 Expression of miR-99a, miR-100 and miR-199b in endometrioid endometrial cancer $(E E C n=34)$ plasma samples in comparison to control group (NE $\mathbf{n}=\mathbf{1 4}$ ). Values are presented in the log scale; * $p<0.0001$ (miR-99a), * $p=0.001$ (miR-100), * $p=0.0007$ (miR-199b). 
1.37-2.82, $\mathrm{p}<0.0001)$ and miR-100 was 1.65-fold upregulated (95\% CI 1.13-2.42, $\mathrm{p}=0.001)$.

Comparison of groups distinguished based on FIGO stage (FIGO IA vs. FIGO > IA) revealed significantly higher expression of miR-99a in plasma of patients with more advanced disease $(p=0.039$, Figure 4$)$. There was no significant association between plasma expression levels of the three miRNAs and grade as well as myometrial invasion.

\section{Diagnostic and prognostic significance of miR-99a, miR-100 and miR-199b}

Receiver operating characteristic (ROC) curves were constructed based on miR-99a, miR-100 and miR-199b expression in tissues and plasma and were used to access utility of single miRNAs to differentiate between EEC and control samples. Resulting ROC curves parameters including AUCs, sensitivity and specificity values and positive and negative predictive values were presented in Table 2. Expression of miR-199b yielded the highest area under curve (AUC) value of 0.704 (95\% CI 0.606-0.794, $\mathrm{p}=0.001)$ in classifying EEC and normal endometrial tissues (Figure 5). The highest AUC value for detection of EEC plasma samples was attributed to miR-99a (0.810, 95\% CI 0.669-0.909, p < 0.0001) (Figure 6). Next, we applied logistic regression analysis in order to assess, if signatures composed of more than one miRNA distinguished EEC and control samples with higher accuracy. The values predicted by obtained models belonged to $<0,1>$ interval and represented the probability of EEC. In the applied regression model probability values $>0.5$ classified samples as malignant. The model is as follows: $p=1 / 1+e^{-z}$, where $e$ is a base of natural logarithm equal to 2.71828 ..., and $z$ is a linear combination of miRNAs expression values $\left(x_{\mathrm{i}}\right)$ weighted by the regression coefficients $\left(b_{\mathrm{i}}\right)$ derived from the multivariate regression analysis: $z=b_{0}+b_{1} x_{1}+b_{2} x_{2}+\ldots+$ $b_{\mathrm{n}} x_{\mathrm{n}}$ [38]. A backward stepwise method revealed that tissue expressions of all three miRNAs were independently associated with EEC and had significant influence on the constructed model $(\mathrm{p}<0.05)$. The 3 -miRNA signature demonstrated higher sensitivity and specificity in distinguishing between cancer and control tissues samples (Additional file 1 and Additional file 2) in comparison to single miRNAs. Similarly, backward logistic regression method revealed that plasma expressions of two miRNAs had significant influence on the model constructed to distinguish EEC and control plasma samples. The 2miRNA signature based on miR-99a and miR-199b expression in plasma was more accurate in comparison to single miRNAs, with $88 \%$ sensitivity and $93 \%$ specificity (Table 2, Additional file 3 and Additional file 2).

Univariate Cox regression analysis revealed association between miR-99a $(\mathrm{p}=0.034)$ and miR-100 $(\mathrm{p}=0.05)$ expression in tissues and overall survival. Moreover, miR-99a $(p=0.002)$ and miR-100 ( $p=0.005)$ were the only independent prognostic markers of overall survival in a multivariate analysis, which included FIGO stage,

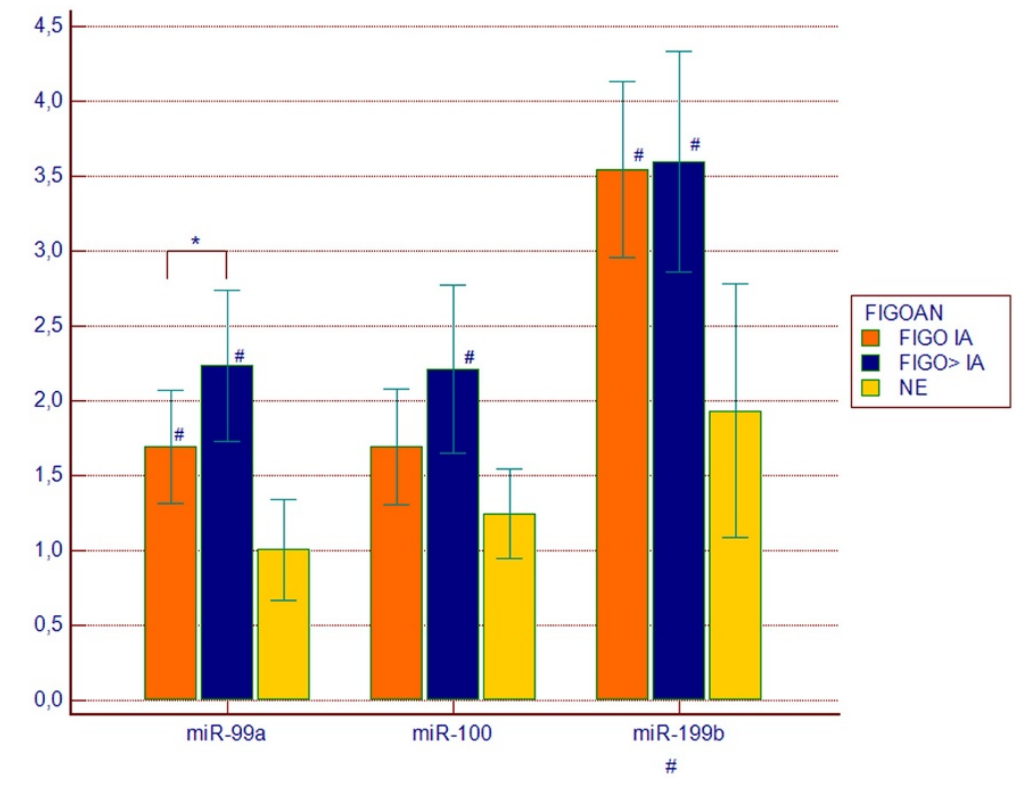

Figure 4 Expression of miR-99a, miR-100 and miR-199b in endometrioid endometrial cancer (EEC) plasma samples in groups distinguished based on FIGO stage. FIGOIA $(n=17)$, FIGO $>I A(n=17), N E$, normal endometrium $(n=14)$. Values are presented in the log scale; * $p=0.039$, \# $p<0.05$. 
Table 2 Receiver operating characteristics curve (ROC) analysis using tissue and plasma miRNAs expression for discriminating endometrioid endometrial cancer (EEC) samples

\begin{tabular}{|c|c|c|c|c|c|c|c|}
\hline miRNA/miRNA signature & $\begin{array}{l}\text { AUC } \\
{[95 \% \mathrm{Cl}]}\end{array}$ & $\mathrm{p}$ & Sensitivity & Specificity & $\mathrm{C}$ & $+\mathrm{PV}$ & $-\mathrm{PV}$ \\
\hline \multicolumn{8}{|l|}{ Tissues ( $E E C n=73$, NE $n=31$ ) } \\
\hline miR-99a & $\begin{array}{l}0.675 \\
{[0.572-0.767]}\end{array}$ & 0.006 & 0.88 & 0.5 & 6.6 & 81.3 & 63.6 \\
\hline miR-100 & $\begin{array}{l}0.652 \\
{[0.548-0.746]}\end{array}$ & 0.03 & 0.86 & 0.5 & 6.5 & 80.8 & 58.3 \\
\hline miR-199b & $\begin{array}{l}0.706 \\
{[0.606-0.794]}\end{array}$ & 0.001 & 0.81 & 0.71 & 5.3 & 87.5 & 60.6 \\
\hline miR-99a/miR-100/miR-199b & $\begin{array}{l}0.774 \\
{[0.678-0.853]}\end{array}$ & $<0.0001$ & 0.61 & 0.89 & 0.76 & 93.3 & 48.1 \\
\hline \multicolumn{8}{|l|}{ Plasma (EEC $n=34$, NE $n=14$ ) } \\
\hline miR-99a & $\begin{array}{l}0.810 \\
{[0.669-0.909]}\end{array}$ & $<0.0001$ & 0.76 & 0.79 & 1.23 & 89.3 & 57.9 \\
\hline miR-100 & $\begin{array}{l}0.740 \\
{[0.592-0.857]}\end{array}$ & 0.001 & 0.64 & 0.79 & 1.5 & 33.3 & 92.8 \\
\hline miR-199b & $\begin{array}{l}0.786 \\
{[0.642-0.892]}\end{array}$ & 0.0002 & 0.79 & 0.71 & 2.48 & 86.7 & 58.8 \\
\hline miR-99a/miR-199b & $\begin{array}{l}0.903 \\
{[0.780-0.970]}\end{array}$ & $<0.0001$ & 0.88 & 0.93 & 0.73 & 96.7 & 76.5 \\
\hline
\end{tabular}

$\overline{A U C}$ - area under curve; $95 \% \mathrm{Cl}-95 \%$ confidence interval; $C$ - factor; $+P V$ - positive predictive value; $-P V$ - negative predictive value.

histological grade, myometrial invasion and the presence of lymph node metastases (Table 3).

In order to generate Kaplan-Meier curves log transformed normalized $\mathrm{Cq}$ values were converted into discrete variables by splitting the samples into "high" and "low" expression group using quartile method. Kaplan-Meier estimation and log rank test confirmed the association with the overall survival in case of miR100 ( $\mathrm{p}=0.02$, HR 0.43, 95\% CI 0.222-0.830) and revealed shorter survival times in a group presenting downregulation of miR-100 expression (Figure 7). In case of miR-99a similar association was observed, though it did

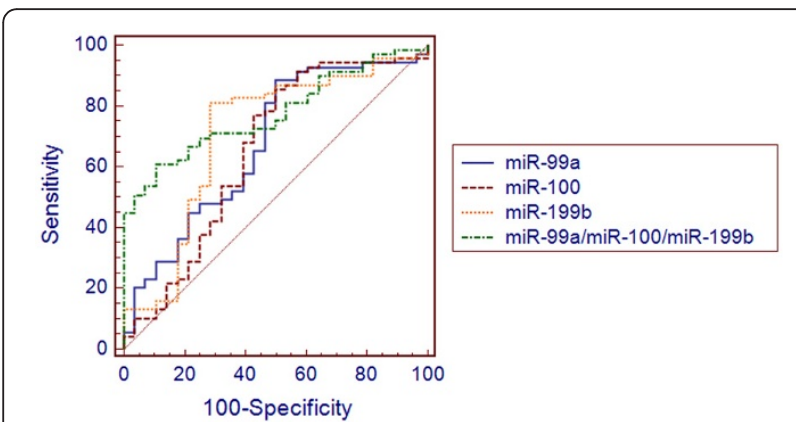

Figure 5 Receiver operating characteristics curve (ROC) analysis using tissue miRNAs expression for discriminating endometrioid endometrial cancer (EEC) samples (EEC $(n=73)$ vs. $N E(n=31)$. A miRNA signature consisting of three miRNAs yielded area under curve (AUC), which was higher in comparison to single miRNAs $(0.774,95 \% \mathrm{Cl} 0.678-0.853, \mathrm{p}<0.0001)$. not reach statistical significance $(\mathrm{p}=0.066$, HR 0.497, 95\% CI 0.252-0.980).

\section{Discussion}

Several studies reported increased expression of mTOR protein and its phosphorylated form (p-mTOR) in endometrial cancer tissues and cell lines. Study by DarbEshafani et al. was one of the first to describe activation of mTOR pathway in a set of human endometrial cancer tissues [16]. Authors found that the activation occurred

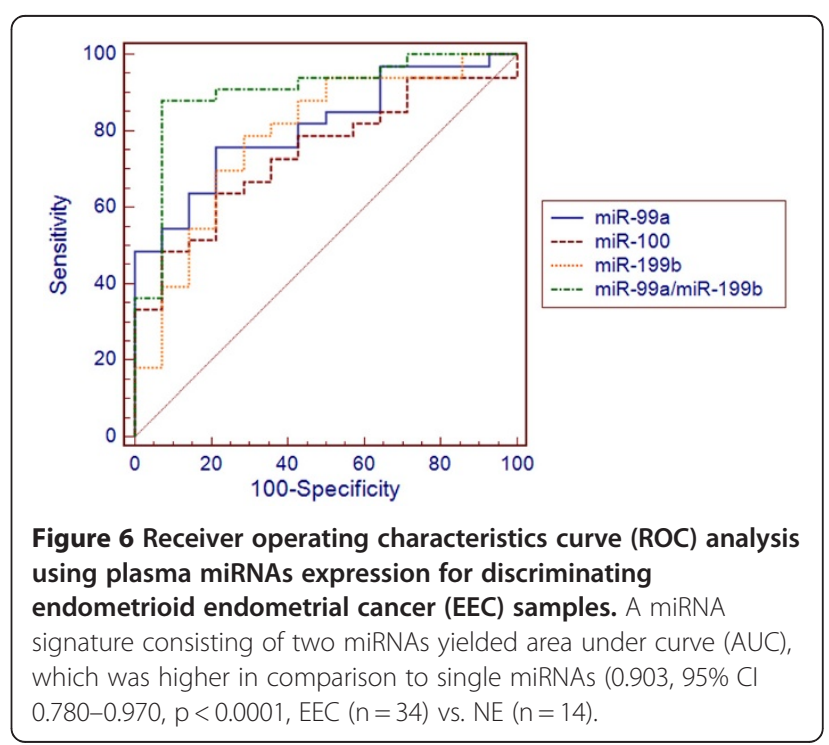


Table 3 Univariate and multivariate analyses of overall survival predictors for patients with EEC

\begin{tabular}{|c|c|c|c|c|c|c|}
\hline & Univari & & & Multiva & & \\
\hline & $\overline{\operatorname{Exp}(b)}$ & $95 \% \mathrm{Cl}$ & $p$ & $\overline{\operatorname{Exp}(b)}$ & $95 \% \mathrm{Cl}$ & $p$ \\
\hline FIGO* & 2.583 & $1.352-4.937$ & 0.004 & 2.938 & $0.419-20.579$ & 0.280 \\
\hline Grade** & 1.358 & $0.685-2.689$ & 0.383 & 0.526 & $0.109-2.539$ & 0.426 \\
\hline Nodes & 3.129 & $1.393-7.024$ & 0.006 & 4.368 & $0.835-22.849$ & 0.082 \\
\hline Myometrial invasion & 0.536 & $0.272-1.054$ & 0.072 & 1.454 & $0.394-5.369$ & 0.576 \\
\hline miR-99a & 0.806 & $0.656-0.989$ & 0.034 & 0.283 & $0.129-0.622$ & 0.002 \\
\hline miR-100 & 0.813 & $0.657-1.007$ & 0.05 & 2.940 & $1.386-6.234$ & 0.005 \\
\hline miR-199b & 0.807 & $0.644-1.012$ & 0.065 & 0.755 & $0.485-1.175$ & 0.216 \\
\hline
\end{tabular}

*FIGO - I vs. II-IV; ** G1-G2 vs. G3; Exp(b) hazard coefficient, 95\% Cl - 95\% confidence interval.

predominantly in high-grade, high-stage tumors [16]. Similar observation was made by Lu et al., who observed mTOR pathway activation in primary tumors and endometrial cancer cell lines, which was associated with decreased expression of mTOR upstream regulators like TSC2, LKB1 and PTEN [39]. In line with those studies $\mathrm{Li}$ et al. reported on activation of mTOR pathway in HEC-1A and Ishikawa cell lines, and found increased expression of mTOR mRNA and higher expression of its downstream substrates in PTEN-deficient Ishikawa cell line [40]. Yoshida et al. pointed at nuclear localization of p-mTOR as an important indicator of poor prognosis and tumor progression, whereas most other authors reported cytoplasmic localization of that kinase [40-42].

A number of studies linked mTOR pathway activation with loss of PTEN and increased AKT expression $[39,42]$. However Mori et al. did not observe any correlation between expression of phosphorylated AKT and PTEN mutations and expression of its downstream effectors including p-mTOR [43]. Moreover, in the study performed by Yoshida et al. there was no association between activated AKT and p-mTOR expression along

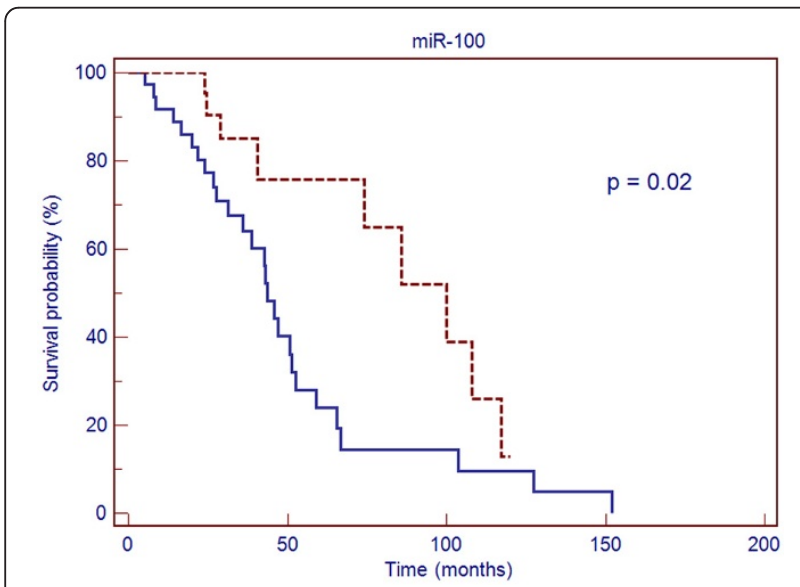

Figure 7 Kaplan-Meier overall survival curve for patients with endometrioid endometrial cancer (EEC) based on miR-100 expression. Red line - values above median, blue line - values below median; HR 0.43, 95\% Cl 0.222-0.830, $p=0.02$. with no correlation between AKT expression and cancer progression or outcome [41]. In accordance with those findings Darb-Esfahani et al. observed activation of mTOR in PTEN willed-type cells, in the absence of activated AKT [16].

Basing on the literature indicating mTOR pathway activation in endometrial tumors several mTOR inhibitors have been studied in this cancer $[44,45]$. Interestingly in the recent, phase II study of temsirolimus in management of patients with recurrent or metastatic endometrial cancer mTOR inhibition did not correlate with PTEN status. In addition authors did not found any relation between expression of phosphorylated AKT, p-mTOR, or phosphorylated S6 and response to treatment or disease progression [46].

Taken together such observations suggest that alternative mechanisms, not related to PTEN/AKT alterations, could play a role in mTOR pathway activation. Based on that assumption we hypothesized that increased expression of mTOR kinase could be caused by alterations in posttranscriptional phases of its biogenesis, which might occur due to disturbed expression of its targeting miRNAs.

Using a quantitive PCR and three experimentally validated endogenous controls we found that mTOR transcripts level was elevated in EEC tissues. In addition we did not observe significant alteration of PTEN mRNA expression, which is a negative upstream regulator of mTOR kinase pathway. Such observation is in accordance with the previous study reporting increased expression of mTOR transcripts and protein in endometrial cancer cell lines as well as with findings presented by Yoshida et al. and Mori et al. [40,41,43]. In addition we have also observed that mTOR mRNA expression tended to be higher in histologically more advanced tumors (G2 and G3 of histological grading). Such finding is in line with the results presented by Darb-Eshafani et al., who observed that mTOR pathway activation was more prevalent in high grade, high stage tumors [16]. Yoshida et al. reported on similar observation, which indicated more pronounced $\mathrm{p}$-mTOR expression in 
endometrial cancer and correlation between nuclear expression of phosphorylated mTOR and worse prognosis [41]. Contrary to those findings, Choi et al. described significantly decreased p-mTOR expression in deep infiltrating endometrial tumors and indicated that expression of p-mTOR predicted better disease-free survival in endometrial cancer patients [47]. No et al. reported on infrequent mTOR expression (7.1\%) in endometrial cancer and did not reveal any correlation between mTOR expression and histological type, grade, stage, myometrial invasion, lymph node metastasis and survival in a large group of 141 patients [48]. In opposition to those observations Wahl et al. observed cytoplasmic p-mTOR expression in $89.2 \%$ of type 1 endometrial carcinomas and Mori et al. found moderate and strong expression of phosphorylated mTOR in $81 \%$ of endometrioid endometrial cancer samples $[42,43]$. Such discrepant findings presented by different authors are difficult to interpret. To some extent they could be explained by histological heterogeneity of sample populations used in some of those studies [48]. However, relations between mTOR kinase expression and EEC biology warrant further evaluation and are particularly important in the context of only moderate responses observed in endometrial cancer patients treated with mTOR pathway inhibitors.

In our study increased level of mTOR mRNA was accompanied by down-regulation of miR-99a, miR-100 and miR-199b, which were found to target this gene in the analysis performed using three in silico algorithms. No previous study reported on the connection between expression of those miRNAs and mTOR transcripts level in endometrial cancer. However, miR-100 was found strongly down-regulated in clear cell ovarian carcinoma and its altered expression was associated with increased expression of mTOR mRNA and protein. Moreover, a direct link between miR-100 and mTOR expression was proven experimentally in the same study. The authors also found that the increase of intracellular miR-100 level enhanced therapeutic effect of mTOR inhibitor in clear cell ovarian carcinoma cell line [49]. Li et al. described down-regulation of miR-99a in hepatocellular carcinoma, which was accompanied by increased expression of its two target genes mTOR and IGF1R. The authors demonstrated, that transfection with miR-99a resulted in mTOR pathway inhibition and cell cycle arrest in that cancer [50]. Chen at al. obtained similar results and observed down-regulation of both mTOR and IGF1R after transfection with miR-99 family members in head and neck squamous cell carcinoma [51]. A connection between decreased expressions of miR-99a, miR-99b and miR-100 and elevated level of mTOR was also described in prostate cancer and was associated with more advanced tumor stage [52]. Important role of miR-199b-5p was found in medulloblastoma. Garzia et al. reported its lower expression in non-metastatic versus metastatic medulloblastomas and observed that over-expression of miR-199b-5p reduced proliferation of medulloblstoma cells in vitro and depleted tumor growth in vivo [53].

Although a number of studies reported alterations in miRNAs expression in endometrial cancer only three studies described down-regulation of miR-199b and miR-99 family members [54-56]. Wu et al. compared miRNA expression in ten EEC samples and ten matching endometrial tissues and found decreased expression of miR-99b [54]. Chung et al. reported down-regulation of miR-199b and the fold change of its expression was similar to the one observed in our study [56]. In the study performed by Snowdon et al. the authors compared normal endometrium, atypical hyperplasia $(\mathrm{AH})$ and EEC samples and found that expression of miR-100 and miR-199b was decreased both in AH and in EEC tissues [55]. Moreover down-regulation of those miRNAs was grater in EEC comparing to $\mathrm{AH}$ samples [55]. In our study a correlation was found between higher histological grade and lower expression of miR-199b and miR-99a. Although Snowdon at al. were not able to perform correlation analysis between histological grade and clinical stage and miRNA expression due to the small size of studied population, the difference between $\mathrm{AH}$ and EEC groups indicated that expression of miR-100 and miR-199b tended to be higher in more advanced stages of endometrial neoplasia [55].

Our study revealed that greater degree of miR-199b and miR-99a down-regulation was attributed to highgrade endometrial tumors. At the same time expression of mTOR kinase mRNA was higher in more histologically advanced tumors, which further supported our hypothesis on the connection between mTOR kinase and studied miRNAs. In addition, there was a significant reverse correlation between expression of all three studied miRNAs and mTOR mRNA expression in matched EEC tissues.

In order to further evaluate the role of miR-99a, miR-100 and miR-199b in EEC we assessed their expression in matched plasma samples obtained from the same group of EEC patients. Surprisingly we found that plasma expression levels of all studied miRNAs were significantly increased in EEC patients in comparison to healthy controls and that expression of miR-99a was higher in patients with clinically more advanced disease. Although the discrepant expression of miR-99a, miR-100 and miR-199b between EEC tissues and plasma is difficult to explain at the time, it could be an additional hallmark of this disease and warrants further investigation. Discrepant expression of another miRNA - miR-92a, was observed in tissue and plasma samples obtained from patients with leukemia, lymphoma and 
hepatocellular carcinoma [57-59]. In the study performed by Tanaka et al. authors observed that miR-92a, which was attributed oncogenic properties, was highly increased in leukemic cells and down-regulated in the plasma of leukemia patients. Authors hypothesized, that apart from transcribing essential miRNAs, cancer cell might specifically take in exosomes containing miR-92a from the blood, which would result in observed decrease of that miRNA in plasma [57]. Ohyashiki et al. reported similar discordant expression of miR-92a in plasma and tumor tissues in non-Hodgkin's lymphoma [58]. Shigoka et al. also found that miR-92a was highly up-regulated in tumors and significantly decreased in plasma of hepatocellular carcinoma patients [59].

Another important aim of our study was to evaluate diagnostic and prognostic values of miR-99a, miR-100 and miR-199b expression in tissues and plasma of EEC patients. For this purpose we constructed ROC curves and developed miRNA signatures, which could classify cancer and control samples with high sensitivity and specificity. The 3-miRNA tissue signature developed using multivariate logistic regression was more accurate in discriminating EEC samples in comparison to single miRNAs. Utility of such signature could potentially facilitate diagnosis in poorly differentiated, disseminated and metastatic tumors. Our study also revealed that the 2-miRNA plasma signature (miR-99a/miR-199b) was very accurate in discriminating EEC samples with sensitivity of $88 \%$ and specificity of $93 \%$. Survival analysis indicated that both miR-99a and miR-100 were significantly associated with prognosis of overall survival and were independent prognostic factors in a multivariate analysis. One of the great challenges for performing qPCR based miRNA expression analysis in tissues and especially in plasma samples is to use proper normalization strategy, which in most cases bases on reference miRNAs or small RNAs. In the presented study normalization was performed using carefully chosen endogenous controls both for tissue and plasma analysis, which increases validity of our results.

To our best knowledge only two previously published studies attempted to evaluate diagnostic and prognostic values of miRNA expression in endometrial cancer tissues.

Corresponding with our results, Chung et al. reported that expression of miR-199b yielded AUC value of 0.837 in detection of EEC tissue samples [56]. Cohn et al. found that miR-199a was more commonly overexpressed in a subset of patients who did not experience recurrence or death from the disease and its down-regulation in endometrial cancer tissues correlated significantly with shorter progression-free and overall survival [60].

Early diagnosis of endometrial cancer is of immense importance as it facilitates radical surgical treatment and prevents the necessity of adjuvant therapy, which can be connected with severe side effects. However, at present no reliable screening strategy is available for this malignancy. We suggest, that after proper validation tissue and plasma miRNA signatures developed in the current study could have a potential to be applied in a clinical setting. Although plasma miRNA signature was highly accurate in distinguishing between EEC and control samples the number of samples used for its development can limit the value of this finding. Therefore we are planning to further investigate and validate our results in a larger group of patients and in the context of other gynecological pathologies.

\section{Conclusions}

We conclude that increased expression of mTOR kinase in endometrioid endometrial cancer coexists with downregulation of its targeting miRNAs, miR-99a, miR-100 and miR-199b, which could suggest a new mechanism of mTOR pathway activation in this malignancy. Although functional studies are necessary to directly prove mTOR regulation by studied miRNAs in EEC, presented results along with studies performed in other tumors seem to support this novel mechanism of altered mTOR kinase pathway. In addition, our findings implicate that miR99a, miR-100 and miR-199b signatures are strongly associated with the diagnosis of endometrioid endometrial carcinoma and after validation in larger groups of patients could be considered promising non-invasive biomarkers for detection and prognosis of this cancer.

\section{Additional files}

Additional file 1: Table S1. Coefficients, standard errors, odds ratios and confidence intervals of miR-99a/miR-100/miR-199b miRNA signature (backward regression model).

Additional file 2: Table S2. Overall model fit of the EEC signatures in tissues (miR-99a/100/199b) and plasma (miR-99a/199b).

Additional file 3: Table S3. Coefficients, standard errors, odds ratios and confidence intervals of miR-99a/miR-199b miRNA signature (backward regression model).

\section{Competing interests}

Authors state that there are no potential conflicts of interest.

\section{Authors' contributions}

AT designed the study, collected samples, performed experiments, analyzed data and wrote the manuscript; KT performed experiments, contributed to manuscript, prepared tables and figures; AP and GZ prepared FFPE samples and collected pathological data; MC and PC provided samples, collected and analyzed clinical data; TP and RM gave technical support and conceptual advice. All authors read and approved the final manuscript.

\section{Acknowledgements}

We thank Drs. Paulina Wdowiak and Joanna Kozak as well as Mrs. Dominika Wilkołek, Msc for their technical help.

The study was supported by grant from Polish Ministry of Science and Higher Education \# IP2010 43670 (to AT). The funding body did not have any role in the design of the study, collection, analysis, and interpretation of 
data; in the writing of the manuscript; or in the decision to submit the manuscript for publication.

\section{Author details}

'Laboratory of Biostructure, Chair and Department of Human Anatomy, Medical University of Lublin, Jaczewskiego 4, Lublin, Poland. ${ }^{2}$ III Chair and Department of Gynecology, Medical University of Lublin, Jaczewskiego 8, Lublin, Poland. ${ }^{3}$ General and Oncologic Surgery Department, Lublin County Specialist Hospital, Al. Kraśnicka 100, Lublin, Poland. ${ }^{4}$ Department of Pathology, Ospedale Sacro Cuore Don Calabria, Via don A. Sempreboni 5, Negrar, Verona, Italy. ${ }^{5}$ Gynecologic Oncology Division, International School of Surgical Anatomy, Ospedale Sacro Cuore Don Calabria, Via don A. Sempreboni 5, Negrar, Verona, Italy. ${ }^{6}$ Department of Obstetrics \& Gynecology, European Gynecology Endoscopy School, Ospedale Sacro Cuore Don Calabria, Via don A. Sempreboni 5, Negrar, Verona, Italy. ${ }^{7}$ Department of Oncology, Ospedale Sacro Cuore Don Calabria, Via don A. Sempreboni 5, Negrar, Verona, Italy. ${ }^{8}$ Department of Pathology, University of Verona, Piazzale L.A. Scuro 10, 37134, Verona, Italy. ${ }^{9}||$ Chair and Department of Surgery, Medical University of Lublin, Staszica 16, 20-081, Lublin, Poland.

Received: 25 May 2012 Accepted: 16 August 2012

Published: 24 August 2012

\section{References}

1. Ferlay J, Parkin DM, Steliarova-Foucher E: Estimates of cancer incidence and mortality in Europe in 2008. Eur J Cancer 2010, 6:765-781.

2. Siegel R, Ward E, Brawley O, Jemal A: Cancer statistics, 2011: the impact of eliminating socioeconomic and racial disparities on premature cancer deaths. CA Cancer J Clin 2011, 61:212-236.

3. Evans T, Sany O, Pearmain P, Ganesan R, Blann A, Sundar S: Differential trends in the rising incidence of endometrial cancer by type: data from a UK population-based registry from 1994 to 2006. Br J Cancer 2011, 104:1505-1510.

4. [Polish Cancer Registry] Krajowy Rejestr Nowotworów. http://epid.coi.waw. $\mathrm{pl} / \mathrm{krn} /$.

5. Bansal N, Yendluri V, Wenham RM: The molecular biology of endometrial cancers and the implications for pathogenesis, classification, and targeted therapies. Cancer Control 2009, 16:8-13.

6. Moreno-Bueno G, Hardisson D, Sarrió D, Sánchez C, Cassia R, Prat J, Herman JG, Esteller M, Matías-Guiu X, Palacios J: Abnormalities of E- and P-cadherin and catenin (beta-, gamma-catenin, and p120ctn) expression in endometrial cancer and endometrial atypical hyperplasia. J Pathol 2003, 199:471-478.

7. Velasco A, Bussaglia E, Pallares J, Dolcet X, Llobet D, Encinas M, Llecha N, Palacios J, Prat J, Matias-Guiu X: PIK3CA gene mutations in endometrial carcinoma: correlation with PTEN and K-RAS alterations. Hum Pathol 2006, 37:1465-1472.

8. Salvesen HB, Stefansson I, Kretzschmar El, Gruber P, MacDonald ND, Ryan A, Jacobs IJ, Akslen LA, Das S: Significance of PTEN alterations in endometrial carcinoma: a population-based study of mutations, promoter methylation and PTEN protein expression. Int I Oncol 2004, 25:1615-1623.

9. Kong D, Suzuki A, Zou TT, Sakurada A, Kemp LW, Wakatsuki S, Yokoyama T, Yamakawa H, Furukawa T, Sato M, Ohuchi N, Sato S, Yin J, Wang S, Abraham JM, Souza RF, Smolinski KN, Meltzer SJ, Horii A: PTEN1 is frequently mutated in primary endometrial carcinomas. Nat Genet 1997, 17:143-144

10. Mutter GL, Lin MC, Fitzgerald JT, Kum JB, Baak JP, Lees JA, Weng LP, Eng C: Altered PTEN expression as a diagnostic marker for the earliest endometrial precancers. J Natl Cancer Inst 2000, 92:924-930.

11. Wullschleger $S$, Loewith $R$, Hall MN: TOR signaling in growth and metabolism. Cell 2006, 124:471-484.

12. Hay N, Sonenberg N: Upstream and downstream of mTOR. Genes Dev 2004, 18:1926-1945.

13. Kim DH, Sarbassov DD, Ali SM, King JE, Latek RR, Erdjument-Bromage H, Tempst P, Sabatini DM: mTOR interacts with raptor to form a nutrientsensitive complex that signals to the cell growth machinery. Cell 2002, 110:163-175.

14. Tokunaga $\mathrm{C}$, Yoshino $\mathrm{K}$, Yonezawa $\mathrm{K}$ : $\mathrm{mTOR}$ integrates amino acid- and energy-sensing pathways. Biochem Biophys Res Commun 2004, 313:443-446.
15. Guertin DA, Sabatini DM: Defining the role of mTOR in cancer. Cancer Cell $2007,12: 9-22$

16. Darb-Esfahani S, Faggad A, Noske A, Weichert W, Buckendahl AC, Müller B, Budczies J, Röske A, Dietel M, Denkert C: Phospho-mTOR and phospho4EBP1 in endometrial adenocarcinoma: association with stage and grade in vivo and link with response to rapamycin treatment in vitro. J Cancer Res Clin Oncol 2009, 135:933-941.

17. Huang J, Manning BD: A complex interplay between Akt, TSC2 and the two mTOR complexes. Biochem Soc Trans 2009, 37:217-222.

18. Gwinn DM, Shackelford DB, Egan DF, Mihaylova MM, Mery A, Vasquez DS, Turk BE, Shaw RJ: AMPK phosphorylation of raptor mediates a metabolic checkpoint. Mol Cell 2008, 30:214-226.

19. Budanov AV, Karin M: $\mathrm{p} 53$ target genes sestrin1 and sestrin2 connect genotoxic stress and mTOR signaling. Cell 2008, 134:451-460.

20. Shen Q, Stanton ML, Feng W, Rodriguez ME, Ramondetta L, Chen L, Brown $R E$, Duan $X$ : Morphoproteomic analysis reveals an overexpressed and constitutively activated phospholipase D1-mTORC2 pathway in endometrial carcinoma. Int $J$ Clin Exp Pathol 2010, 4:13-21.

21. Sayed D, Abdellatif M: MicroRNAs in development and disease. Physiol Rev 2011, 91:827-887.

22. Farazi TA, Spitzer Jl, Morozov P, Tuschl T: miRNAs in human cancer. J Pathol 2011, 223:102-115

23. Guo H, Ingolia NT, Weissman JS, Bartel DP: Mammalian microRNAs predominantly act to decrease target mRNA levels. Nature 2010, 466:835-840.

24. Lewin SN: Revised FIGO staging system for endometrial cancer. Clin Obstet Gynecol 2011, 54:215-218.

25. Pfaffl MW: A new mathematical model for relative quantification in realtime RT-PCR. Nucleic Acids Res 2001, 29:e45.

26. Peltier HJ, Latham GJ: Normalization of microRNA expression levels in quantitative RT-PCR assays: identification of suitable reference RNA targets in normal and cancerous human solid tissues. RNA 2008 14:844-852.

27. Wong L, Lee K, Russell I, Chen C: Endogenous Controls for Real-Time Quantitation of miRNA Using TaqMan ${ }^{\circledR}$ MicroRNA Assays. Applied Biosystems Application Note 2007, Publication 127AP11-01. http://www appliedbiosystems.com.

28. Liang $Y$, Ridzon D, Wong $L$, Chen C: Characterization of microRNA expression profiles in normal human tissues. BMC Genomics 2007, 8:166.

29. Bargaje R, Hariharan M, Scaria V, Pillai B: Consensus miRNA expression profiles derived from interplatform normalization of microarray data. RNA 2010, 16:16-25.

30. Mitchell PS, Parkin RK, Kroh EM, Fritz BR, Wyman SK, Pogosova-Agadjanyan EL, Peterson A, Noteboom J, O'Briant KC, Allen A, Lin DW, Urban N, Drescher CW, Knudsen BS, Stirewalt DL, Gentleman R, Vessella RL, Nelson PS, Martin DB: Tewari: Circulating microRNAs as stable blood-based markers for cancer detection. Proc Natl Acad Sci U S A 2008, 105:10513-10518.

31. Kroh EM, Parkin RK, Mitchell PS, Tewari M: Analysis of circulating microRNA biomarkers in plasma and serum using quantitative reverse transcription-PCR (qRT-PCR). Methods 2010, 50:298-301.

32. Chen $\mathrm{X}$, Bonnefoi $\mathrm{H}$, Diebold-Berger $\mathrm{S}$, Lyautey J, Lederrey $\mathrm{C}$, Faltin-Traub $\mathrm{E}$, Stroun M, Anker P: Detecting tumor-related alterations in plasma or serum DNA of patients diagnosed with breast cancer. Clin Cancer Res 1999, 5:2297-303.

33. Resnick KE, Alder H, Hagan JP, Richardson DL, Croce CM, Cohn DE: The detection of differentially expressed microRNAs from the serum of ovarian cancer patients using a novel real-time PCR platform. Gynecol Oncol 2009, 112:55-59.

34. Lawrie CH, Gal S, Dunlop HM, Pushkaran B, Liggins AP, Pulford K, Banham AH, Pezzella F, Boultwood J, Wainscoat JS, Hatton CS, Harris AL: Detection of elevated levels of tumour-associated microRNAs in serum of patients with diffuse large B-cell lymphoma. Br J Haematol 2008, 141:672-675.

35. Profiling of microRNA in Blood, Serum/Plasma. http://www.exiqon.com/ls/ Documents/Scientific/microRNA-serum-plasma-quidelines.pdf.

36. Andersen $\mathrm{CL}$, Jensen JL, Ørntoft TF: Normalization of real-time quantitative reverse transcription-PCR data: a model-based variance estimation approach to identify genes suited for normalization, applied to bladder and colon cancer data sets. Cancer Res 2004, 64:5245-250. 
37. Hellemans J, Mortier G, De Paepe A, Speleman F, Vandesompele J: qBase relative quantification framework and software for management and automated analysis of real-time quantitative PCR data. Genome Biol 2007, 8:R19.

38. Hosmer DW, Lemeshow S: Applied logistic regression. New York, NY: WileyInterscience; 1989.

39. Lu KH, Wu W, Dave B, Slomovitz BM, Burke TW, Munsell MF, Broaddus RR, Walker CL: Loss of tuberous sclerosis complex-2 function and activation of mammalian target of rapamycin signaling in endometrial carcinoma. Clin Cancer Res 2008, 14:2543-2550.

40. Li X, Xiao L, Yang Y, Shen H, Zeng H, Wang Z: The expression of mammalian target of rapamycin in Ishikawa and HEC-1A cells. J Huazhong Univ Sci Technolog Med Sci 2008, 28:340-342.

41. Yoshida Y, Kurokawa T, Horiuchi Y, Sawamura Y, Shinagawa A, Kotsuji F: Localisation of phosphorylated mTOR expression is critical to tumour progression and outcomes in patients with endometrial cancer. Eur $\mathrm{J}$ Cancer 2010, 46:3445-3452.

42. Wahl H, Daudi S, Kshirsagar M, Griffith K, Tan L, Rhode J, Liu JR: Expression of metabolically targeted biomarkers in endometrial carcinoma. Gynecol Oncol 2010, 116:21-27.

43. Mori N, Kyo S, Sakaguchi J, Mizumoto Y, Ohno S, Maida Y, Hashimoto M, Takakura M, Inoue M: Concomitant activation of AKT with extracellularregulated kinase $1 / 2$ occurs independently of PTEN or PIK3CA mutations in endometrial cancer and may be associated with favorable prognosiss. Cancer Sci 2007, 98:1881-1888.

44. Gadducci A, Cosio S, Genazzani AR: Old and new perspectives in the pharmacological treatment of advanced or recurrent endometrial cancer: Hormonal therapy, chemotherapy and molecularly targeted therapies. Crit Rev Oncol Hematol 2006, 58:242-256.

45. Slomovitz BM, Lu KH, Johnston T, Coleman RL, Munsell M, Broaddus RR, Walker C, Ramondetta LM, Burke TW, Gershenson DM, Wolf J: A phase 2 study of the oral mammalian target of rapamycin inhibitor, everolimus, in patients with recurrent endometrial carcinoma. Cancer 2010, 116:5415-5419.

46. Oza AM, Elit L, Tsao MS, Kamel-Reid S, Biagi J, Provencher DM, Gotlieb WH, Hoskins PJ, Ghatage P, Tonkin KS, Mackay HJ, Mazurka J, Sederias J, Ivy P, Dancey JE, Eisenhauer EA: Phase II study of temsirolimus in women with recurrent or metastatic endometrial cancer: a trial of the NCIC Clinical Trials Group. J Clin Oncol 2011, 29:3278-3285.

47. Choi CH, Lee JS, Kim SR, Kim TJ, Lee JW, Kim BG, Bae DS: Clinical significance of pmTOR expression in endometrioid endometria carcinoma. Eur J Obstet Gynecol Reprod Biol 2010, 153:207-210.

48. No JH, Jeon YT, Park IA, Kang D, Kim JW, Park NH, Kang SB, Song YS: Expression of $\mathrm{mTOR}$ protein and its clinical significance in endometrial cancer. Med Sci Monit 2009, 15:BR301-BR305.

49. Nagaraja AK, Creighton CJ, Yu Z, Zhu H, Gunaratne PH, Reid JG, Olokpa E, Itamochi H, Ueno NT, Hawkins SM, Anderson ML, Matzuk MM: A link between mir-100 and FRAP1/mTOR in clear cell ovarian cancer. Mol Endocrinol 2010, 24:447-463.

50. Li D, Liu X, Lin L, Hou J, Li N, Wang C, Wang P, Zhang Q, Zhang P, Zhou W, Wang Z, Ding G, Zhuang SM, Zheng L, Tao W, Cao X: MicroRNA-99a Inhibits Hepatocellular Carcinoma Growth and Correlates with Prognosis of Patients with Hepatocellular Carcinoma. J Biol Chem 2011, 286:36677-36685.

51. Chen Z, Jin Y, Yu D, Wang A, Mahjabeen I, Wang C, Liu X, Zhou X: Downregulation of the microRNA-99 family members in head and neck squamous cell carcinoma. Oral Oncol, in press.

52. Sun D, Lee YS, Malhotra A, Kim HK, Matecic M, Evans C, Jensen RV, Moskaluk CA, Dutta A: miR-99 family of MicroRNAs suppresses the expression of prostate-specific antigen and prostate cancer cell proliferation. Cancer Res 2011, 71:1313-1324.

53. Garzia L, Andolfo I, Cusanelli E, Marino N, Petrosino G, De Martino D, Esposito V, Galeone A, Navas L, Esposito S, Gargiulo S, Fattet S, Donofrio V, Cinalli G, Brunetti A, Vecchio LD, Northcott PA, Delattre O, Taylor MD, Iolascon A, Zollo M: MicroRNA-199b-5p impairs cancer stem cells through negative regulation of HES1 in medulloblastoma. PLoS One 2009, 4:e4998.

54. Wu W, Lin Z, Zhuang Z, Liang X: Expression profile of mammalian microRNAs in endometrioid adenocarcinoma. Eur J Cancer Prev 2009, 18:50-55.

55. Snowdon J, Zhang X, Childs T, Tron VA, Feilotter H: The microRNA-200 family is upregulated in endometrial carcinoma. PLoS One 2011, 6:e22828.
56. Chung TK, Lau TS, Cheung TH, Yim SF, Lo KW, Siu NS, Chan LK, Yu MY, Kwong J, Doran G, Barroilhet LM, Ng AS, Wong RR, Wang WW, Mok SC, Smith DI, Berkowitz RS, Wong YF: Dysregulation of microRNA-204 mediates migration and invasion of endometrial cancer by regulating FOXC1. Int J Cancer 2012, 130:1036-1045.

57. Tanaka M, Oikawa K, Takanashi M, Kudo M, Ohyashiki J, Ohyashiki K, Kuroda M: Down-regulation of miR-92 in human plasma is a novel marker for acute leukemia patients. PLoS One 2009, 4:e5532.

58. Ohyashiki K, Umezu T, Yoshizawa S, Ito Y, Ohyashiki M, Kawashima H, Tanaka M, Kuroda M, Ohyashiki JH: Clinical impact of down-regulated plasma miR-92a levels in non-Hodgkin's lymphoma. PLoS One 2011, 6:e16408.

59. Shigoka M, Tsuchida A, Matsudo T, Nagakawa Y, Saito H, Suzuki Y, Aoki T, Murakami Y, Toyoda H, Kumada T, Bartenschlager R, Kato N, Ikeda M, Takashina T, Tanaka M, Suzuki R, Oikawa K, Takanashi M, Kuroda M: Deregulation of miR-92a expression is implicated in hepatocellular carcinoma development. Pathol Int 2010, 60:351-357.

60. Cohn DE, Fabbri M, Valeri N, Alder H, Ivanov I, Liu CG, Croce CM, Resnick KE: Comprehensive miRNA profiling of surgically staged endometrial cancer. Am J Obstet Gynecol 2010, 202:656.e1-e8.

doi:10.1186/1471-2407-12-369

Cite this article as: Torres et al:: Deregulation of miR-100, miR-99a and miR-199b in tissues and plasma coexists with increased expression of mTOR kinase in endometrioid endometrial carcinoma. BMC Cancer 2012 $12: 369$.

\section{Submit your next manuscript to BioMed Central and take full advantage of:}

- Convenient online submission

- Thorough peer review

- No space constraints or color figure charges

- Immediate publication on acceptance

- Inclusion in PubMed, CAS, Scopus and Google Scholar

- Research which is freely available for redistribution 